\title{
Assessment of Saturated Hydraulic Conductivity of Red and Lateritic Soils under Diverse Land Topography and Vegetation Using Classical Statistical Analysis
}

\author{
B.G. Momin ${ }^{1 *}$, R. Ray ${ }^{1}$ and S.K. Patra ${ }^{2}$ \\ ${ }^{1}$ Department of Soil and Water Conservation, ${ }^{2}$ Department of Agricultural Chemistry and Soil \\ Science, Bidhan Chandra Krishi Viswavidyalaya, Mohanpur- 741 252, West Bengal, India \\ *Corresponding author
}

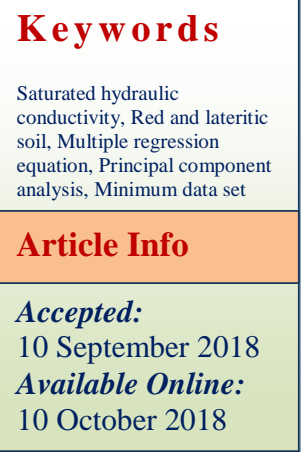

\section{Introduction}

Saturated hydraulic conductivity (Ks) is an essential soil physical property which determines the capacity of the soil to transmit water through its pore spaces and largely controls the soil-plant-water relations and processes. Understanding of the variation in $\mathrm{Ks}$ is important for planning irrigation and drainage design, crop and groundwater modeling, and level of intrusion of toxic
Saturated hydraulic conductivity of the red and lateritic soils was assessed from the basic properties using multivariate analysis techniques. The descriptive statistics showed that all the soil variables were normally distributed and mostly displayed moderate to strong correlation with each other. The stepwise multiple regression equation demonstrated that clay fraction was the key indicator in explaining most variability of the saturated hydraulic conductivity. The principal component analysis (PCA) was applied to reduce the number of original variables. It indicated that sand, particle density and porosity were the highest loaded variables in the first PCs; while silt, water holding capacity, porosity, electrical conductivity and organic carbon in the second PCs and clay, bulk density and water holding capacity in the third PCs, which altogether predicted $93.4 \%$ of the total variance. The regressive model for saturated hydraulic conductivity using minimum data set (MDS) from PCA such as sand, silt and WHC accounted for $94.3 \%$ of the variance was highly predictive than the other models studied. The MDS model may thus provide a potential tool for assessing the saturated hydraulic conductivity of the soils. 
Paramasivam, 1995; Mathan and Mahendra, 1993; Ndiaye et al., 2007; Wang et al., 2012; Chaudhari et al., 2015; Bardhan et al., 2016). In addition, the different land use and land cover systems, vegetation, topography and climate also greatly controls the hydraulic characteristics of the soil mainly by way of alteration of soil physical, chemical and biological environment (Newaj et al., 2007). Many direct methods have been developed over time for measurement of saturated hydraulic conductivity in the laboratory and field conditions (Klute and Dirksen, 1986).

However, these practices are both time consuming, costly and laborious and often fail to represent in a wide range of circumstances and for all soil types because of the associated soil heterogeneity and experimental errors (Saikia and Singh, 2003; Zhang et al., 2007). In field condition there is large spatial and temporal variability on the measurements of soil Ks, indicating the necessity for an inexpensive and rapid way to determine the soil Ks. Therefore, several indirect methods have been proposed to estimate the saturated hydraulic conductivity from easily measured soil properties in order to reduce the effort and cost (Wösten and van Genuchten, 1988; Patil et al., 2009). The application of classical statistical methods for prediction of saturated hydraulic conductivity is considered to be excellent tools which intended to translate laboratory measured soil variables into soil hydraulic properties. In these approaches, the correlation matrix, multiple regression equations and the principal component analysis (PCA) for data reduction were used to select a few more interpretable soil components from the list of large data sets of soil properties. These provisions proved to be good predictive indicators for unknown soil hydraulic characteristics (Aimrun, 2009). The purpose of the present study was to investigate the saturated hydraulic conductivity of red and lateritic soils having varying land topography and vegetation, where the crop production depends largely on rainfall and irrigation. The objectives were to develop some predictive models on the saturated hydraulic conductivity of the soil modified by soil properties, topography and land use systems and its interrelations with other measured soil properties.

\section{Materials and Methods}

\section{Study area}

The experimental site represents the semi-arid red and lateritic agro-climatic zone of West Bengal, India (Figure 1). It is located between $22.43^{\circ}$ and $23.84^{\circ} \mathrm{N}$ latitude and $87.06^{\circ}$ and $87.86^{\circ}$ E longitude with altitudes ranging between 10.5 and $78.8 \mathrm{~m}$ above mean sea level. Physiographically the area is primarily characterized by undulating and rolling topography with numerous mounds and valley. The area consists of high, medium and low land with gentle slope in all directions. The climate is humid sub-tropical with long hot summer and short cold winter. The temperature ranges between 25.5 and $41.5{ }^{\circ} \mathrm{C}$ during summer and 12.7 to $18.3{ }^{\circ} \mathrm{C}$ during winter. The annual precipitation varies from $1100 \mathrm{~mm}$ to $1300 \mathrm{~mm}$ with more than $75-80 \%$ of it being received during June through September. Agriculture is mostly rainfed during wet season (June-September) and harvestable rainfall and groundwater irrigated during dry season (October-May). The groundwater resource in the area is overexploited and the depth of groundwater is receding day by day. Frequent moisture stress even during the wet season is witnessed. Taxonomically the soil is classified as fine loamy, mixed, hyperthermic Haplustalfs. Paddy is the principal crop of the area. The other major crops are wheat, mustard, sesame, pulses, and vegetables. A large portion of land remained fallow during the winter and dry seasons. 


\section{Soil sampling and laboratory analyses}

One hundred thirty five (135) soil profile samples were collected from three land positions (high, medium and low) at three depths $(0-15,15-30$ and $30-45 \mathrm{~cm})$ with three paddy based cropping systems (paddyvegetable, paddy-mustard and paddy-fallow) from five districts (Purulia, Birbhum, Bardhaman, Bankura and Medinipur) representing the semi-arid red and lateritic agro-climatic zone of West Bengal, India. The samples after collection were cleaned, airdried in shade and crushed to pass through a 2 $\mathrm{mm}$ size sieve. Each soil profile layer from three land situations and cropping system of five different districts was then thoroughly mixed up to make twenty seven (27) number of composite homogeneous soils samples corresponding to the particular depth, land situation and cropping system. Standard analytical methods employed for determination of the physical, hydro-physical and chemical properties of the soils were international pipette sampling method for particle size distribution (Piper, 1966), core method for bulk density and particle density and saturation method for porosity (Black, 1965), potentiometric method for soil $\mathrm{pH}$ and saturated soil paste extraction for electrical conductivity (Jackson, 1973), ammonium acetate extraction method for cation exchange capacity (Schollenberger and Simon, 1945), wet digestion method for soil organic carbon (Walkley and Black, 1934). Saturated hydraulic conductivity of the soil samples were measured according to constant head method (Bouma et al., 1981). This procedure allowed water to move through the soil under a steady state head condition while the quantity (volume) of water flowing through the soil specimen was measured over a period of time. The saturated hydraulic conductivity (Ks) using constant head method was calculated by the equation: $\mathrm{Ks}=\frac{\mathrm{Q} \Delta \mathrm{L}}{\mathrm{AT \Delta H}}$ where,
$\mathrm{Q}$ is quantity of water discharged in time, $\Delta \mathrm{L}$ is soil length, A is cross-sectional area of soil, $\mathrm{T}$ is total time of discharge and $\Delta \mathrm{H}$ is hydraulic head difference.

\section{Statistical analyses}

Various classical statistical methods were employed for analyzing the measured data base. Soil parameters were analyzed using basic descriptive statistics to obtain the minimum, maximum, mean, median, standard deviation and coefficient of variation (Table 1). A skewness-kurtosis test was performed to verify whether the observations were normally distributed. The skewness for a normal distribution should be zero, but a value between minus and plus one is deemed acceptable in statistical analyses. The strength of interrelations between the observed soil variables was examined by Pearson correlation matrix (Table 2) to identify the most important dependent variables for inclusion in the principal component analysis (PCA). The PCA is a multivariate technique of covariance structure modeling which transformed the observed variables linearly into orthogonal uncorrelated variables known as principal components (PCs), which maintained the total variance in the original data. The PCA was performed on the correlation matrix, which in effect standardized data measured on different scales to unit variance. As a result, the PCs became independent of the scales and units of the observed variables. The output from PCA comprised the eigenvalues, eigenvectors and weighted loading scores. The eigenvalues gave the variance accounted for by each component and the PCs are ranked accordingly (Table 5). The first PC explained most of the variation; subsequent components were orthogonal to one another and uncorrelated, with reducing variance accounted for. Principal components with eigenvalues $<1$ were disregarded because they 
accounted for less information than the original variable. Only the PCs with eigenvalues $>1$ and could explain at least 5\% of the data variation were considered for identifying the MDS (minimum data set). The indicators receiving weighted loading values between the highest and 10\% reduction of the highest weighted loading were selected for the MDSs for each PC. The uncorrelated variables in any PC were also selected in MDSs. The multiple linear regression analysis as developed by using the selected MDSs for soil variables for prediction of the saturated hydraulic conductivity (Ks) of the soils was verified for their significance by coefficient of regression $\left(R^{2}\right)$, adjusted $R^{2}$ and standard error of estimate $\left(\mathrm{SE}_{\mathrm{est}}\right)$ values. In the step-wise regressive predictive models, the saturated hydraulic conductivity was used as the dependent variable and other soil factors as the independent variables. All the independent soil variables were allowed to enter into the models competitively and the sequence of entry depended upon their contribution to the models. The levels of significance at which variables entered and stayed into the models were set at $P \leq 0.05$. The estimated coefficient of determination $\left(\mathrm{R}^{2}\right)$ indicated the relative suitability of different soil variables in the prediction of the saturated hydraulic conductivity. All statistical analyses were worked out by using SPSS 16.0 version and Excel software.

\section{Results and Discussion}

\section{Descriptive statistics for soil properties}

The average sand, silt and clay fractions varied from 30.52 to $62.44,16.21$ to 35.82 and 14.30 to $35.17 \%$, respectively, portraying that the soils were sandy loam to clay loam in texture (Table 1). The soils were relatively finer in sub-surface horizons than in surface horizon, indicating the occurrence of clay Illuviation under pedogenic as well as anthropogenic processes (Rudramurthy et al., 2007). The bulk density (BD) and particle density (PD) of the soils ranged from 1.13 to $1.49 \mathrm{Mg} / \mathrm{m}^{3}$ and 2.35 to $2.68 \mathrm{Mg} / \mathrm{m}^{3}$, respectively. Higher values with increasing depth could be attributed to higher fine particles (Sahu and Mishra, 1997) and greater compactness and reduced organic matter content (Walia and Rao, 1997) in surface soil than in sub-soils. The results corroborated with the findings of Rudramurthy et al., (2007) who reported higher BD in surface soil than the sub-surface soils in paddy land use system manifested due to the collapse of noncapillary pores and formation of impervious layer beneath the plough layer as result of puddling operation. The soil porosity ranged between 26.44 and $36.54 \%$ and decreased with depth in all the pedons. This was related to the increased sand fraction in surface soil causing increased non-capillary pore which resulted in the improved saturated hydraulic conductivity of the soils. Other plausible reasons might be the increased bulk density and particle density of the soils down the profile (Rudramurthy et al., 2007).

The value of water holding capacity (WHC) of soils ranging from 23.97 to $35.87 \%$ increased with depth. Higher amount of finer silt and clay particles in sub-soils as compared with the surface soil resulted in higher WHC. Saturated hydraulic conductivity of the soils varied from 18.27 to $25.41 \mathrm{~cm} / \mathrm{hr}$. The value decreased with increasing depth of the profile and quantum of distribution followed almost the same trend as in sand. Soil $\mathrm{pH}$ was strongly to mildly acidic in nature (5.45 and $60)$ and increased with increase in soil depth. The electrical conductivity (EC) of the soils varied from 0.13 to $0.38 \mathrm{dS} / \mathrm{m}$ with an average value of $0.28 \mathrm{dS} / \mathrm{m}$ and the distribution pattern was almost similar to soil $\mathrm{pH}$. The organic carbon contents were low to medium (2.3 to $6.1 \mathrm{~g} / \mathrm{kg}$ ) and decreased with depth. Maximum organic carbon content in surface soil as 
compared with sub-surface soils was probably due to accumulation of organic matter and crop residues aided by restricted downward leaching due to impervious sub-surface layers. The cation exchange capacity varied from 6.10 to $16.22 \mathrm{cmol} / \mathrm{kg}$ and increased with increase in soil depth.

Descriptive statistics of soil properties at different soil depths under varying land positions and cropping systems are shown in Table 1. Based on the skewness and kurtosis, all the soil variables could be described as having a normal distribution. The standard deviation for most soil properties varied substantially indicating high to low variability. Sand, silt and clay fractions along with hydraulic conductivity, electrical conductivity, organic carbon and cation exchange capacity were highly variable, while water holding capacity was moderately variable and bulk density, particle density, porosity and soil $\mathrm{pH}$ seemed to be least variable.

\section{Correlation matrix of saturated hydraulic conductivity}

Most of the soil variables had moderate to strong correlation with each other. A significant positive correlation was found between saturated hydraulic conductivity $(\mathrm{Ks})$ and sand particles $\left(\mathrm{r}=0.805^{* *}\right), \mathrm{PD}\left(\mathrm{r}=0.250^{*}\right)$ and porosity $\left(\mathrm{r}=0.712^{* *}\right)$ and a negative correlation with silt $\left(\mathrm{r}=-0.273^{*}\right)$, clay $(\mathrm{r}=-$ $\left.0.968^{* *}\right), \mathrm{BD}\left(\mathrm{r}=-0.319^{* *}\right), \mathrm{pH}\left(\mathrm{r}=-0.284^{* *}\right)$, EC $\left(\mathrm{r}=-0.543^{* *}\right)$, OC $\left(\mathrm{r}=-0.336^{* *}\right)$ and CEC $\left(\mathrm{r}=-0.899^{* *}\right)$ values of the soils (Table 2$)$.

This indicates that increase in sand and decrease in clay and silt contents did contribute to the enhancement of the $\mathrm{Ks}$ presumably due to the increase in noncapillary pores in the soils. This shows the dependence of soil Ks on the variability of soil texture. Such finding was reported by Kisku et al., (2017) in cultivated soils. These significantly correlated soil parameters were identified as the most eligible independent indicators for principal component analysis for predicting the Ks of the soils.

\section{Regressive models for saturated hydraulic conductivity}

In the linear regressive models developed, only two independent variables out of a large data set of raw soil variables were involved for predicting the saturated hydraulic conductivity of the soils. The first variable accommodated in the model was negatively correlated clay fraction which could explain $93.4 \%$ of the total variation in the saturated hydraulic conductivity (Table 3 ). The second variable entered into the model was positively correlated porosity which improved the $\mathrm{R}^{2}$ to 0.951. In other words, the inclusion of two independent soil variables i.e. clay and porosity could measure $95.1 \%$ of the variability in saturated hydraulic conductivity of soils. However, clay fraction was found to be the key indicator in the predictive models and thereby largely regulates the saturated hydraulic conductivity of the soils.

\section{Principal component analysis for predicting saturated hydraulic conductivity}

The principal component analysis (PCA) showed that different soil factors in each component have differential contribution in predicting the variance of saturated hydraulic conductivity of the soils (Table 4).

The three principal components (PC) with eigenvalues $>1$ and that explain $5 \%$ of the total variance were retained and these factors altogether accounted for $86.62 \%$ of the variance in saturated hydraulic conductivity (Table 5). The first PCs explained $43.25 \%$ of the variation where sand, particle density and porosity were the highly negatively loaded variables (Figure 2). 
Table.1 Descriptive statistics for soil saturated hydraulic conductivity and soil properties

\begin{tabular}{|c|c|c|c|c|c|c|c|c|c|}
\hline Variable & Minimum & Maximum & Range & Mean & Median & Standard deviation & Skewness & Kurtosis & CV (\%) \\
\hline Sand $(\%)$ & 30.52 & 62.44 & 31.92 & 48.46 & 52.14 & 10.35 & -0.48 & -1.33 & 21.36 \\
\hline Silt (\%) & 16.21 & 35.82 & 19.61 & 25.28 & 24.96 & 6.06 & 0.21 & -1.34 & 23.97 \\
\hline Clay $(\%)$ & 14.30 & 35.17 & 20.87 & 26.22 & 28.85 & 6.88 & -0.48 & -1.36 & 26.24 \\
\hline BD $\left(\mathrm{Mg} / \mathrm{m}^{3}\right)$ & 1.13 & 1.49 & 0.36 & 1.35 & 1.34 & 0.07 & -0.22 & 0.11 & 5.19 \\
\hline PD $\left(\mathrm{Mg} / \mathrm{m}^{3}\right)$ & 2.35 & 2.68 & 0.33 & 2.61 & 2.63 & 0.06 & -1.83 & 4.12 & 2.30 \\
\hline Porosity (\%) & 26.44 & 36.54 & 10.10 & 31.34 & 31.25 & 2.20 & 0.12 & -0.23 & 7.02 \\
\hline WHC (\%) & 23.97 & 35.87 & 11.90 & 30.10 & 30.34 & 3.48 & -0.19 & -0.98 & 11.56 \\
\hline $\mathrm{HC}(\mathrm{cm} / \mathrm{hr})$ & 18.22 & 38.87 & 20.65 & 27.55 & 25.46 & 6.03 & 0.42 & -1.04 & 21.89 \\
\hline $\mathrm{pH}(1: 2.5)$ & 5.45 & 6.60 & 1.15 & 5.90 & 5.80 & 0.34 & 0.62 & -1.05 & 5.76 \\
\hline $\mathrm{EC}(\mathrm{dS} / \mathrm{m})$ & 0.13 & 0.38 & 0.25 & 0.28 & 0.29 & 0.07 & -0.37 & -1.03 & 25.00 \\
\hline Org. C (g/kg) & 2.30 & 6.10 & 3.80 & 4.74 & 5.30 & 1.05 & -0.86 & -0.41 & 22.15 \\
\hline CEC (cmol/kg) & 6.10 & 16.62 & 10.52 & 11.84 & 12.50 & 3.20 & -0.21 & -1.24 & 27.03 \\
\hline
\end{tabular}

BD: bulk density, PD: particle density, WHC: water holding capacity, HC: hydraulic capacity, EC: electrical conductivity, Org. C: organic carbon, CEC: cation exchange capacity, CV: coefficient of variation

Table.2 Linear correlation coefficient matrix between soil hydraulic conductivity and soil properties

\begin{tabular}{|c|c|c|c|c|c|c|c|c|c|c|c|}
\hline Variables & Sand & Silt & Clay & BD & PD & WHC & Porosity & $\mathrm{HC}$ & pH & $\mathbf{E C}$ & Org. C \\
\hline Silt & $-0.766 * *$ & & & & & & & & & & \\
\hline Clay & $-0.826 * *$ & $0.271 *$ & & & & & & & & & \\
\hline BD & $-0.290 * *$ & 0.180 & $0.271 * *$ & & & & & & & & \\
\hline PD & $0.493 * *$ & $-0.453 * *$ & $-0.339 * *$ & 0.159 & & & & & & & \\
\hline WHC & $-0.303 * *$ & $0.446 * *$ & 0.063 & -0.132 & $-0.475 * *$ & & & & & & \\
\hline Porosity & $0.530 * *$ & -0.182 & $-0.636 * *$ & $-0.624 * *$ & $-0.243^{*}$ & 0.079 & & & & & \\
\hline $\mathrm{HC}$ & $0.805^{* *}$ & $-0.273^{*}$ & $-0.968 * *$ & $-0.319 * *$ & $0.250 *$ & -0.054 & $0.712 * *$ & & & & \\
\hline pH & 0.058 & $-0.344 * *$ & 0.213 & $0.558 * *$ & $0.519 * *$ & $-0.398 * *$ & $-0.658 * *$ & $-0.284 * *$ & & & \\
\hline $\mathrm{EC}$ & $-0.514 * *$ & 0.138 & $0.645^{* *}$ & $-0.226^{*}$ & $-0.503 * *$ & 0.203 & -0.043 & $-0.543 * *$ & $-0.236 *$ & & \\
\hline Org. C & $-0.347 * *$ & 0.091 & $0.437 * *$ & $-0.451 * *$ & $-0.486 * *$ & -0.018 & $0.280^{*}$ & $-0.336 * *$ & $-0.430 * *$ & $0.788 * *$ & \\
\hline CEC & $-0.925 * *$ & $0.540 * *$ & $0.912 * *$ & $0.363 * *$ & $-0.392 * *$ & 0.204 & $-0.671 * *$ & $-0.899 * *$ & 0.180 & $0.571 * *$ & $0.308 * *$ \\
\hline
\end{tabular}

*, ** indicate significant at 5\% and 1\% levels of probability, respectively; BD: bulk density, PD: particle density, WHC: water holding capacity, HC: hydraulic capacity, EC: electrical conductivity, Org. C: organic carbon, CEC: cation exchange capacity 
Table.3 Stepwise multiple regression equation of saturated hydraulic conductivity (Y) with different soil variables

\begin{tabular}{c|l|c|c|r} 
Model & Regression equation & $\mathbf{R}^{2}$ & Adjusted $\mathbf{R}^{2}$ & SE $_{\text {est. }}$ \\
\hline $\mathbf{1}$ & $\mathrm{Y}=49.815-0.849$ clay & 0.934 & 0.934 & 1.553 \\
\hline $\mathbf{2}$ & $\mathrm{Y}=33.242-0.757$ clay +0.452 porosity & 0.951 & 0.949 & 1.355 \\
\hline
\end{tabular}

Table.4 Principal component loading matrix for soil properties for predicting variance of hydraulic conductivity

\begin{tabular}{|l|c|c|c|}
\hline \multirow{2}{*}{ Variables } & \multicolumn{3}{|c|}{ Principal components } \\
\hline Sand & PC-1 & PC-2 & PC-3 \\
\hline Silt & $\mathbf{- 0 . 9 4 8}$ & -0.057 & 0.275 \\
\hline Clay & 0.545 & $\mathbf{0 . 2 4 4}$ & $\mathbf{- 0 . 7 5 1}$ \\
\hline BD & 0.942 & -0.129 & 0.248 \\
\hline PD & 0.303 & -0.708 & $\mathbf{- 0 . 3 4 9}$ \\
\hline WHC & $\mathbf{- 0 . 4 6 2}$ & -0.649 & 0.205 \\
\hline Porosity & 0.116 & $\mathbf{0 . 8 6 5}$ & $\mathbf{- 0 . 1 8 4}$ \\
\hline pH & $\mathbf{- 0 . 5 9 1}$ & $\mathbf{0 . 7 4 2}$ & 0.037 \\
\hline EC & $\mathbf{- 0 . 0 7 8}$ & -0.865 & 0.258 \\
\hline OC & 0.667 & $\mathbf{0 . 4 3 5}$ & 0.462 \\
\hline CEC & 0.445 & $\mathbf{0 . 6 7 7}$ & 0.463 \\
\hline Hydraulic conductivity & 0.974 & -0.127 & $\mathbf{- 0 . 0 4 4}$ \\
\hline Bold vales indicte highly & $\mathbf{- 0 . 9 1 7}$ & $\mathbf{0 . 2 3 3}$ & $\mathbf{- 0 . 2 0 6}$ \\
\hline
\end{tabular}

Bold values indicate highly weighted variables for the respective principal components $(P C)$

Table.5 Eigen value, variance accounted for and cumulative variance from a principal component analysis

\begin{tabular}{|l|}
\hline Parameter \\
\hline Eigenvalue \\
\hline Proportion of variance explained (\%) \\
\hline Cumulative proportion of variance explained (\%) \\
\hline
\end{tabular}

\begin{tabular}{|c|c|c|}
\hline \multicolumn{3}{|c|}{ Principal component number } \\
\hline PC-1 & PC-2 & PC-3 \\
\hline 5.190 & 3.767 & 1.439 \\
\hline 43.25 & 31.39 & 11.99 \\
\hline 43.25 & 74.63 & 86.62 \\
\hline
\end{tabular}

Fig.1 Location map of the study area with insets of India and West Bengal

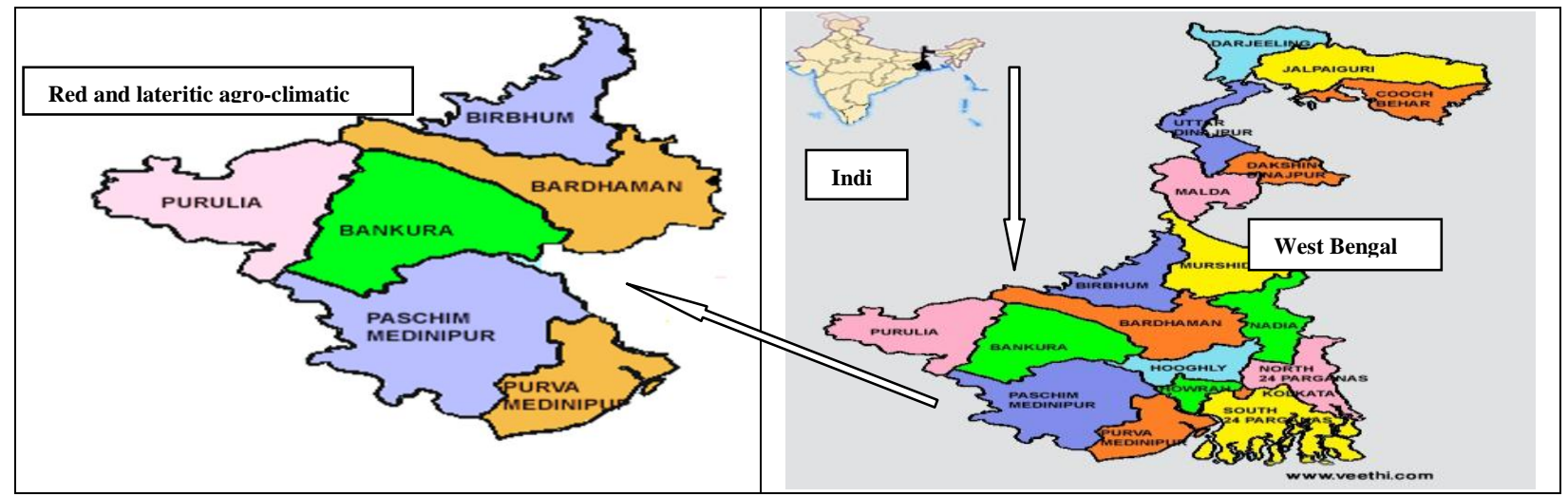


Fig.2 Scatter diagram of different regression factor scores of all sequences for first two components due to PCA

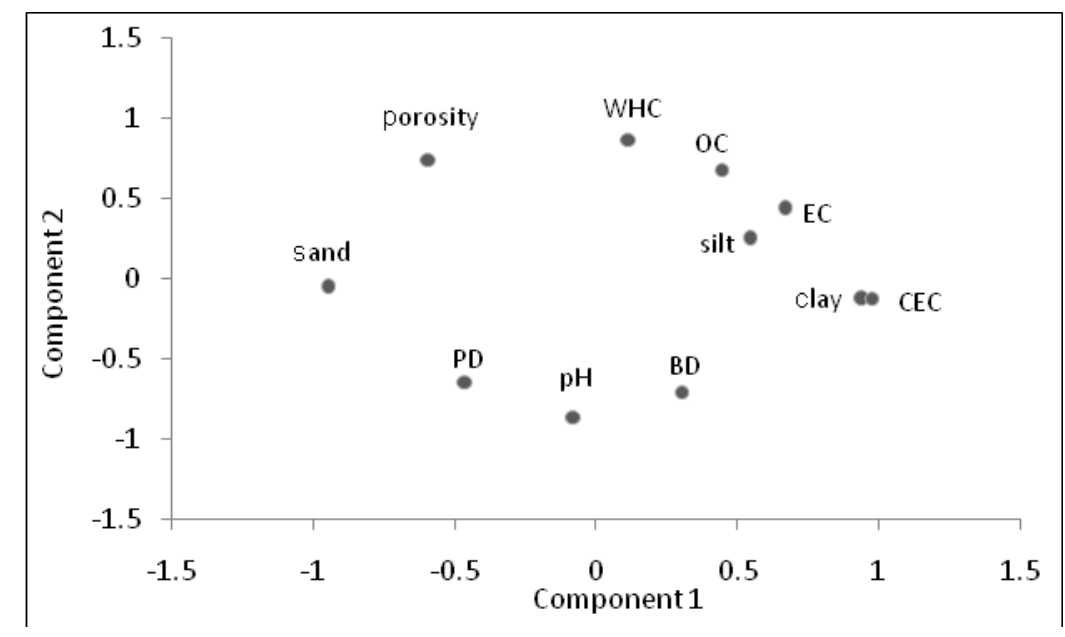

The second PCs described $31.39 \%$ of the variance, wherein silt, water holding capacity, porosity, electrical conductivity and organic carbon were highly positively loaded variables. The third PCs were small and could predict $11.99 \%$ of the variance. It was regulated by the negatively loaded variables like clay, bulk density and water holding capacity. However, the indicators in the first and second components in PCA could explain the most variability $(74.63 \%)$ of the total variance. This finding reveals that the soil texture and structure appear to be related in the maximum determination of the saturated hydraulic conductivity of the soils.

\section{Minimum data set for predicting saturated hydraulic conductivity}

The minimum data set (MDS) variables having eigenvalues more than one were selected based upon PCA technique and the resulted component matrix where from highest negatively loaded variable sand fraction from first component, highest positively loaded variable water holding capacity from second component and highest negatively loaded variable silt fraction from third component were selected as independent MDS variables (Tables 4 and 5). The uncorrelated variables were also selected in MDS along with the highest loaded variable. A model regression equation was thus developed keeping saturated hydraulic conductivity (Ks) as dependent variable and MDSs as predictor or independent variables as $\mathrm{Ks}=-55.696+0.828$ sand $^{* *}+0.771$ silt** +0.319 WHC $^{*}$, where $* P<0.05, * * P<0.01$; $\mathrm{R}^{2}=0.943$, Adjusted $\mathrm{R}^{2}=0.940$, $\mathrm{S}_{\text {Eest. }}=$ 1.471. The model for Ks using MDS did not include porosity and organic carbon as the effective indicators and thus excluded from the model. However, the MDS model for Ks through PCA technique was highly predictive than the PCA. This may be explained that several other soil factors assigned with PCA study might have contributed negative role in predicting the saturated hydraulic conductivity of the soils.

Most of the soil variables was normally distributed and displayed moderate to strong correlation. Multiple regression equation showed that clay fraction was the principal indicator in predicting $93.4 \%$ of the variance in soil Ks. The principal component analysis (PCA) indicated that three components explained $93.4 \%$ of the variance. The regressive model for Ks using MDS like sand, silt and water holding capacity could assess 
$94.3 \%$ of the variability of Ks. The MDS through PCA technique and other associated statistical tools may thus provide an alternative way of assessing the saturated hydraulic conductivity indirectly from the measured basic soil properties.

\section{References}

Aimrun, W. and Amin, M. S.M. 2000. Pedotransfer function for saturated hydraulic conductivity of lowland paddy soils. Paddy Water Environ., 7(3): 217-225.

Bardhan, G., Russo, D., Goldstein, D., Levy, G.J. 2016. Changes in the hydraulic properties of a clay soil under long-term irrigation with treated wastewater, Geoderma, 264 A(15):1-9.

Black, C. A. 1965. Methods of Soil Analysis. Part I and II. American Society of Agronomy, Inc., Madison, Wisconsin, USA.

Bouma, J., van Hoorn, J.W. and Stoffelsen, G. H. 1981. Measuring the hydraulic conductivity of soil adjacent to tile drains in a heavy clay soil in The Netherlands. J. Hydrol., 50: 371-381.

Chaudhari, S.K., Bardhan, G., Kumar, P., Singh, R., Mishra, A. K., Rai, P., Singh, K. and Shar-ma, D. K. 2015. ShortTerm Tillage and Residue Management Impact on Physical Properties of a Reclaimed Sodic Soil. J. Indian Soc. Soil Sci., 63(1): 30-38.

Firky, S. A. 1990. Hydraulic conductivity of alluvial soils as affected by some physical and chemical properties. Agricutural Research Review, 68(2): 305-310.

Jackson, M. L. 1973. Soil Chemical Analysis $\left(2^{\text {nd }}\right.$ edn.). Prentice Hall of India Private Limited, New Delhi, India, pp 109-182.

Kisku, T.K., Datta, A., Basak, N., Mandi, S., Hembram, S. and Roy, R. 2017. Evaluation of saturated hydraulic conductivity from soil properties in an
Inceptisol using different land cover and depths. J. Appl. Natr. Sci., 9(3): 1482 1488.

Klute, A. and Dirksen, C. 1986. Hydraulic conductivity of saturated soils. In: Klute, A. (Ed.), Methods of Soil Analysis. ASA \& SSSA, Madison, Wisconsin, USA, pp. 694-700.

Mathan, K. K. and Mahendran, P. P. 1993. Hydraulic conductivity of vertic Haplusalfs in relation to soil properties. J. Indian Soc. Soil Sci., 41: 759-761.

Ndiaye, B., Molenat, J., Hallair, V., Gascual, C. and Hamon, Y. 2007. Effects of agricultural practices on hydraulic properties and water movement in soils in Britanny (France). Soil Tillage Res., 93(2): 251-263.

Newaj, R., Dar, S. A., Bhargava, M. K. and Yadav, R. S. 2007. Effects of management practices on growth of white siris (Albia procera), grain yield of intercrops, weed population and soil fertility changes in agrisilvi-culture system in semi-arid India. Indian $\mathrm{J}$. Agric. Sci., 77(7): 403-407.

Paramasivam, P. 1995. Infiltration rate, hydraulic conductivity and moisture retention characteristics of some soils of lower Bhavani project command area, Tamil Nadu. Madras Agric. J., 82(3): 190-192.

Patil, N. G. and Singh, S. K. 2016. Pedotransfer functions for estimation soil hydraulic properties. Pedosphere, 26(4): 417-430.

Patil, N. G., Prasad, J., Srivastava, R. and Dhale, S. A. 2009. Estimation of water retention characteristics of shrink-swell soils using pedotransfer functions. J. Indian Soc. Soil Sci., 57(3): 273-279.

Piper, C. S. 1966. Soil and Plant Analysis, Hans Publishers, Bombay.

Rudramurthy, H. V., Puttaiah, E. T., Vageesh, T. S. and Gurumurthy, B. R. 2007. Physical environmental qualities of soils 
under different land use systems in Shimoga district of Karnataka. Karnataka J. Agric. Sci., 20(2): 370374.

Sahu, S. C. and Mishra, K. N. 1997. Morphological characteristics and classification of soils of an irrigated flood plain in eastern coastal region. J. Indian Soc. Soil Sci., 45: 152-156.

Saikia, U. S. and Singh, A. K. 2003. Development and validation of pedotransfer functions for water retention, saturated hydraulic conductivity and aggregate stability of soils of Banha watershed. J. Indian Soc. Soil Sci., 51: 484-488.

Schollenberger, C. J. and Simon, R. H. 1945. Determination of exchange capacity and exchangeable bases in soil-ammonium acetate method. Soil Sci., 59: 13-24.

Walia, C. S. and Rao, Y. S. 1997. Characteristics and classification of some soils of trans-Yamuna plain. J. Indian Soc. Soil Sci., 45: 156-162.

Walkley, A. and Black, I. A. 1934. An examination of the Degtjareff method for determining soil organic matter and a proposed modification of the chromic acid titration method. Soil Sci., 37: 2938.

Wang, Y., Shao, M. and Liu, Z. 2012. Pedotransfer functions for predicting soil hydraulic properties of the Chinese loess plateau. Soil Sci., 177(7): 424432.

Wijaya, K., Nishimura, T., Setiawan, B. I. and Saptomo, S. K. 2010. Spatial variability of soil saturated hydraulic conductivity in paddy field in accordance to subsurface percolation. Paddy Water Environ., 8(2): 113-120.

Wösten, J. H. M. and van Genuchten, M. T. 1988. Using texture and other soil properties to predict the unsaturated hydraulic conductivity. Soil Sci. Soc. Am. J., 52: 1762-1770.

Zhang, S., Lövdahl, L. Grip, H. and Tong, Y. (007. Soil hydraulic properties of two loess soils in China measured by various field-scale and laboratory methods. Catena, 69: 264-273.

\section{How to cite this article:}

Momin, B.G., R. Ray and Patra, S.K. 2018. Assessment of Saturated Hydraulic Conductivity of Red and Lateritic Soils under Diverse Land Topography and Vegetation Using Classical Statistical Analysis. Int.J.Curr.Microbiol.App.Sci. 7(10): 963-972.

doi: https://doi.org/10.20546/ijcmas.2018.710.107 